\title{
Cardiovascular risk during early adult life. Risk markers among participants in "Live for Life" health promotion programme in Sweden
}

\author{
Lars-Göran Persson, Kjell Lindström, Hans Lingfors, Calle Bengtsson, Lauren Lissner
}

\begin{abstract}
Study objective-To study differences in cardiovascular lifestyle risk factors and biological risk markers in early adult life, with special attention to age and sex differences. Lifestyle cardiovascular risk factors included dietary habits, physical inactivity, smoking, alcohol habits, psychosocial strain, and mental stress. Biological risk markers included anthropometric variables, arterial blood pressure, and serum cholesterol concentration.
\end{abstract}

Design-A combined individual and community based preventive programme, including health examinations.

Setting-All communities in the County of Skaraborg in south western Sweden.

Participants-Altogether 12982 men and women aged 30 or 35 years who underwent health examinations over seven years.

Main results-In both sexes, biological risk markers studied were worse in 35 year old subjects than in 30 year olds. Furthermore, a larger proportion of men aged 35 years were smokers and were physically inactive compared with 30 year old men. However, dietary habits were better in both sexes in the upper age group. At both ages there were also significant differences between men and women. Women, compared with men, had better dietary habits and lower alcohol consumption but smoked more and experienced greater mental stress and psychosocial strain. All biological risk markers were worse in men than in women at both ages studied. During the observation period, some improvement of the health profile of the participants was observed, indicating a beneficial effect of the intervention programme.

Conclusions-The results indicate that the risk of cardiovascular disease, as assessed from studying lifestyle and biological risk markers, increases early in life, suggesting that preventive measures should start early.

(F Epidemiol Community Health 1998;52:425-432)

Cardiovascular diseases are the most common cause of death before the age of 65 in men in Sweden and second among women. ${ }^{1}$ To achieve a reduction in premature death from cardiovascular diseases, it seems most appropriate to combine an intervention programme directed towards the total population with a targeted strategy aiming at risk factor improvement in high risk people. ${ }^{2}$ Such a combined strategy was used when a preventive programme, Live for Life, was started in 1989 in the County of Skaraborg in south western Sweden. The preventive programme was developed cooperatively by hospital and primary health care physicians and approved by the regional political authorities. The plan was based on experiences from a previous study of men aged 33-42 at Habo, ${ }^{3}$ one of 17 communities of the County of Skaraborg. In Live for Life a volontary health examination is offered to residents 30 and 35 years of age as part of the routine activities of the primary health care centres. The purpose of this paper is to present an overeview of the Live for Life programme with some results from the health examinations during the first seven years. Special reference is given to age and sex differences, as our knowledge about such differences is limited during early adult life.

\section{Methods}

STUDY POPULATION

At the beginning of 1989 , the year when the first health examination started, altogether 272215 persons were living the County of Skaraborg. At the end of each year, preceding the year of examination, the County Council of Skaraborg provided a list of male and female residents aged 30 and 35 years. The local authorities in each community decided whether to take part in the programme. With a few exceptions, because of organisational problems, all health care centres invited 35 year old inhabitants living in the health centre area. Some health centres also decided to invite inhabitants aged 30 years. A single letter of invitation was sent. Pregnant women and women who had recently given birth were asked to mail a reply in order to be called for an examination the next year.

The main responsibility for carrying out the Live for Live programme has during the total period been given to the primary health care personnel. At least one nurse at each of the health centres of the county obtained special training in prevention, as did the general practitioners. The nurses and the general practitioners from different parts of the county meet regularly to exchange their experiences and to further increase their knowledge about preventive work. The programme has been approved by the Ethics Committee of the Göteborg University. 
Table 1 Number of participants and estimated participation rate (\%) during the years 1-5 in the "Live for Life" programme in the County of Skaraborg

\begin{tabular}{lll}
\hline Sex and age $(y)$ & Number & $\%$ \\
\hline Men, 30 & 1776 & 51.8 \\
Women, 30 & 1988 & 66.6 \\
Men, 35 & 4332 & 61.7 \\
Women, 35 & 4886 & 73.2 \\
Total & 12982 & 64.9 \\
\hline
\end{tabular}

PARTICIPATION

During the first five years a total of 12982 persons were examined. Subjects from the population list were eligible if still living in the area at the time of examination. Table 1 shows the participation during the first five years until 31 December 1993 among 30 year old men and women born in 1959-1963 and 35 year old men and women born in 1954-1958. During 1994 and 1995, another 3532 subjects were examined. Of these, 367 men and 412 women aged 35 had been examined also in 1989-1990, at the age of 30 years. An estimation of the participation rate, based on a registration by the nurses, of participants and non-participants during the first six months of each year, starting from 1990, is also shown in table 1. The overall participation rate during the period 19901993 was according to this registration $64.9 \%$. The participation rate was similar during the first and second halves of the year according to a substudy described below highlighting this question: $66.7 \%$ and $70.9 \%$ in men and $77.1 \%$ and $75.0 \%$ in women, respectively.

To make a rough participation/nonparticipation characterisation, substudies were carried out in selected health centre areas. Thus, participation during the first six months of year 4 was compared with that during the last six months of the same year in one of the communities. To study the effect of not including 30 year old subjects at all health centres, a comparison was made during the second year between 35 year old participants at health centres to which 30 year old subjects were invited and those to which they were not. Additionally, health centres with a participation rate below $70 \%$ during the fourth year were compared with health centres with a participation rate over $70 \%$. It could be concluded from these substudies that the participants were mainly representative of men and women in the County of Skaraborg of the ages studied.

POPULATION BASED PROGRAMME

The population based programme includes health education to food shop personnel and information to the population via newspapers, periodicals, and radio.

\section{INDIVIDUAL BASED PROGRAMME}

Men and women who are invited to the health examinations receive a personal invitation about four weeks in advance including information about the examination and the subsequent health dialogue. Those who agree to participate are sent a questionnaire, mainly dealing with lifestyle and psychosocial factors, to be completed at home before the examination. The health examination is carried out by specially trained nurses at the health centres.

\section{Health profile}

This health profile grades 12 generally accepted risk factors for coronary heart disease and premature death according to degree of risk and, in addition, prevalence of chronic disease (table 2 and fig 1 ). The intention with the health profile is to evoke an interest for lifestyle among the participants in the dialogue with the nurse, and to use it as a base for intervention measures. Different colours for different risk levels reinforce the pedagogic message. Red is used for high risk, green for low risk, and yellow for intermediate risk. The separate factors included in the profile have been given $1-3$ or 1-4 risk points as shown in table 1 . The aim is to give two risk points if the relative risk of myocardial infarction and premature death is estimated to be increased by one to two times compared with one risk point, three risk points if the relative risk is estimated to be increased two to three times, and four risk points if the risk is estimated to be increased by more than three times. Some of the risk factors, body mass index (BMI), waist to hip circumference ratio (WHR), and serum cholesterol concentration, are given different gradings for men and women. The grading of risk points was based

Table 2 Health profile with limit values for classification into different risk groups ("risk points")

\begin{tabular}{|c|c|c|c|c|}
\hline & \multicolumn{4}{|l|}{ Risk points } \\
\hline & 1 & 2 & 3 & 4 \\
\hline Use of tobacco ${ }^{\star}($ cigarettes/d) & 0 & $1-14$ & $15-24$ & $\geqslant 25$ \\
\hline Alcohol intake† (cl/week) & $<18$ & $18-36$ & $37-75$ & $>75$ \\
\hline Dietary habits (dietary points $\ddagger)$ & $3-5$ & $6-8$ & $9-11$ & - \\
\hline Physical activity (kcal/week) & $>2000$ & $500-2000$ & $<500$ & - \\
\hline Psychosocial strain (strain points $\ddagger$ ) & $<2$ & $2-3$ & $4-5$ & - \\
\hline Mental stress (stress points $\ddagger$ ) & $<3$ & $3-4$ & $5-7$ & - \\
\hline \multirow[t]{2}{*}{$\mathrm{BMI}\left(\mathrm{kg} / \mathrm{m}^{2}\right)$} & $\mathrm{M}:<27$ & $27-36$ & $\geqslant 37$ & - \\
\hline & $\mathrm{F}:<29$ & $29-38$ & $\geqslant 39$ & - \\
\hline \multirow[t]{2}{*}{ WHR } & $\mathrm{M}:<0.90$ & $0.90-0.94$ & $0.95-0.99$ & $\geqslant 1.00$ \\
\hline & $\mathrm{F}:<0.75$ & $0.75-0.79$ & $0.80-0.84$ & $\geqslant 0.85$ \\
\hline \multirow[t]{2}{*}{ Cholesterol (mmol/l) } & $M:<5.2$ & $5.2-6.4$ & $6.5-9.0$ & $>9.0$ \\
\hline & $\mathrm{F}:<5.2$ & $5.2-7.0$ & $7.1-9.0$ & $>9.0$ \\
\hline Diastolic blood pressure $(\mathrm{mm} \mathrm{Hg})$ & $<95$ & 95-104 & $105-114$ & $\geqslant 115$ \\
\hline Family history of diabetes $\$ & 0 & 1 & $\geqslant 2$ & - \\
\hline \multirow[t]{2}{*}{ Family history of cardiovascular disease (age, y) } & Father: $\geqslant 70$ & $55-69$ & $45-54$ & $<45$ \\
\hline & Mother: $\geqslant 75$ & $60-74$ & $50-59$ & $<50$ \\
\hline Chronic disease & According to & & & \\
\hline
\end{tabular}

$\star$ Use of moist snuff but no smoking gives 2 risk points for tobacco. $†$ Calculated to $40 \%$ alcohol ( 1 cl equivalent to $3.16 \mathrm{~g}$ alcohol). $\ddagger$ Points according to questionnaire. §Number of parents or siblings with history of diabetes. 
Health curve

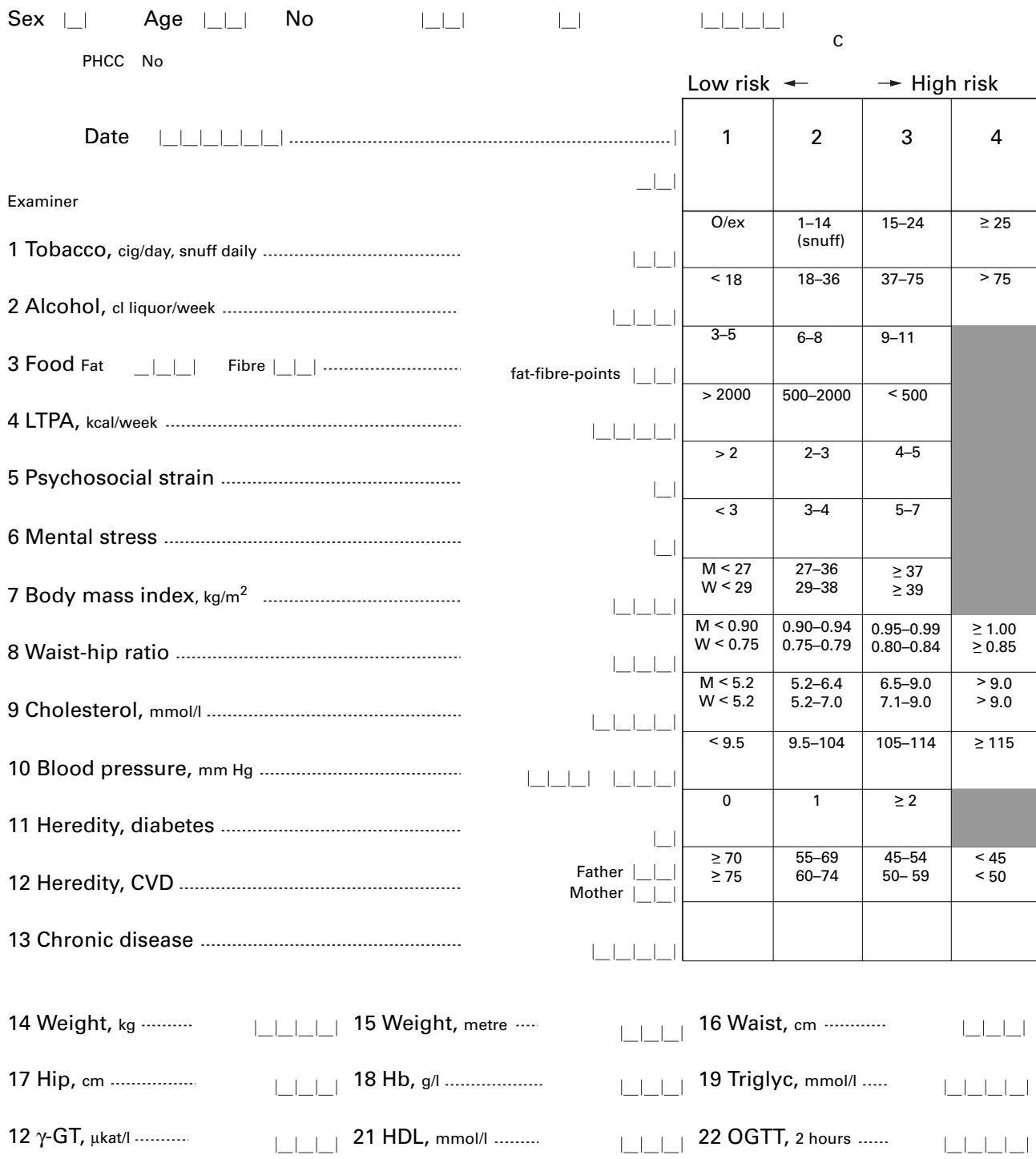

Figure 1 The health profile used in the Live for Life programme ("Health Curve").

on the results from previous population studies including experiences from the one in Habo. ${ }^{3} \mathrm{It}$ may be pointed out that the grading is made to give a crude estimation only.

\section{Lifestyle factors}

Use of tobacco is calculated from the general questionnaire as grams of tobacco smoked per day equivalent to cigarettes per day. Those who do not smoke but use moist snuff daily, which is especially popular among young Swedish men, are given risk point 2 for tobacco.

Alcohol intake is estimated from the general questionnaire and calculated as mean intake of of $40 \%$ alcohol (cl) per week, corresponding to the percentage of alcohol in the traditional Swedish liquor. To obtain information about problems of addiction, the four CAGE questions ${ }^{4}$ are additionally used.

Dietary habits are studied by means of a special food frequency questionnaire, which has been validated against a three day food record, with satisfactory results. ${ }^{5}$ The dietary questionnaire is based on 20 questions and has proved to be useful for estimating semiquantitatively the intake of dietary fat and the proportion of fibre in the diet. Risk points are based on the points estimated from fat and fibre intake according to the questionnaire. A copy of the completed dietary questionnaire including specific recommendations relating to the different food types is given to the participant.

Physical activity at leisure time is estimated from the general questionnaire by dividing the subjects into four activity groups. ${ }^{6}$ To those who state that they are moderately active (groups 2 and 3), a supplementary questionnaire is given. This questionnaire estimates, in a quantitative way, the amount of energy expended at leisure time as well as when commuting to work, for example, walking or cycling. The mean time per week for each specified physical activity is estimated and multiplied by an intensity factor, resulting in an 
estimation in $\mathrm{kcal} / \mathrm{week}$. This intensity factor is slightly modified after the Minnesota LTPA questionnaire $^{7}$ and after Passemore and Durnin. ${ }^{8}$ The energy expenditure is estimated for each of the four seasons, and the mean of this is calculated.

The classification of psychosocial strain into risk points is based on information obtained from the general questionnaire. The questions deal with employment, family situation, economic factors, social network, and presence of close confidants. Based on these questions, points are assigned: unemployment or threat of unemployment (two points); economical problems (one point); not being married or living alone (one point); and absence of a close confidant (one point).

Information about mental stress is obtained from a $50 \mathrm{~mm}$ visual scale associated with items in the general questionnaire. On this scale the participants are asked to mark their feeling of mental stress during the last year, where $0 \mathrm{~mm}$ indicates no stress and $50 \mathrm{~mm}$ means maximal stress. Stress points are calculated from this scale, where $20-34 \mathrm{~mm}$ is assigned one stress point, $35-44 \mathrm{~mm}$ two stress points, and $45-50 \mathrm{~mm}$ three stress points. Finally, based on four special questions about sleeping problems, general fatigue, depression and anxiety, each alternative answer yields one stress point. Total number of stress points was calculated by adding all of these stress points.

\section{Biological risk markers}

Anthropometric measurements include body height, body weight, and waist and hip circumferences. Body height is measured to the nearest $\mathrm{cm}$ with the subject standing without shoes. Body weight is measured to the nearest $0.1 \mathrm{~kg}$ with the subject wearing light clothes (trousers, skirt, shirt). BMI is then calculated as weight/ height $^{2}\left(\mathrm{~kg} / \mathrm{m}^{2}\right)$. Waist circumference $(\mathrm{cm})$ is measured at the level of the navel after ordinary expiration and the hip circumference at the widest site between waist and buttocks. WHR is calculated as waist circumference divided by hip circumference.

Capillary blood is sampled for measurement of serum cholesterol concentration. The concentrations are measured immediately by means of a Reflotron (Boehringer Mannheim), located at each participating health centre.

Arterial blood pressure is measured to the nearest $2 \mathrm{~mm} \mathrm{Hg}$ with the subject in the seated position after at least a rest of five minutes. A mercury sphygmomanometer is used with a cuff $12 \times 35 \mathrm{~cm}$ and, if the arm circumference is $>32 \mathrm{~cm}$, a $15 \times 43 \mathrm{~cm}$ cuff.

\section{Genetic factors}

Family history of diabetes is based on the number of persons with diabetes among parents or siblings as stated in the questionnaire. Family history of cardiovascular disease is also based on information from the general questionnaire about myocardial infarction or stroke among parents and refers to age of mother or father when she or he first had such an event.

\section{KEY POINTS}

- Biological risk markers for cardiovascular disease were more pronounced at the age of 35 years than at the age of 30 .

- Dietary habits were more favourable at the age of 35 years than at the age of 30 , both in men and women.

- Smoking and psychosocial risk factors indicated higher risk in women; diet and biological markers indicated higher risk in men.

- The results from this intervention programme with respect to cardiovascular risk factors indicate that prevention should start early in life.

\section{Prevalence of chronic diseases}

Chronic diseases include myocardial infarction, cancer, arterial hypertension, diabetes, and angina pectoris. These conditions are graded in cooperation with a doctor according to a special instruction manual where, for example, diabetes means risk point 4 , angina pectoris risk point 3 or 4 depending upon severity, and well controlled hypertension risk point 2 . Angina pectoris is defined according to Rose. $^{9}$

\section{HEALTH DIALOGUE}

The health profile is checked by the nurse, and a copy is given to the participant. Every participant has a health dialogue with the nurse about his or her risk factors, their interrelationships, and the best ways to improve well being and to lower total risk. The health profile serves as an educational tool in this dialogue. When appropriate, the nurse arranges a second meeting with the participant, or the participant is referred to a general practitioner at the health centre, to a psychologist, to some other member of the health centre's team, or to group activities. The intervention aims at a lifestyle modification chosen by the participant such as smoking cessation, increased physical activity, improved diet, and stress management.

\section{STATISTICAL METHODS}

The extended $\chi^{2}$ test (tables $2 \times 3$ ) was used to test the hypothesis of no difference between frequencies (table 3). Student's $t$ test was used for testing the hypothesis of no difference between mean values (tables 4-6). Two tailed tests were used, and $p$ values $<0.05$ were considered statistically significant. The statistical analysis program of Application System version 2.2 and Epi-Info version 5.01 were used.

\section{Results}

INFLUENCE OF AGE

\section{Lifestyle factors}

Table 3 shows the distribution of lifestyle factors according to the classification described in table 2. Men aged 35 had a better dietary intake than men aged 30, but they were less physically active, and they experienced more mental stress. A larger proportion of men aged 35 were smokers compared with men aged 30 , 
Table 3 Distribution of risk points (\%) for lifestyle factors and psychosocial factors during the first five years for each age and sex group, and statistical analyses: $I=$ age comparison men, $I I=$ age comparison women, $I I I=$ sex comparison age 30 , IV=sex comparison age 35

\begin{tabular}{|c|c|c|c|c|c|c|c|c|c|c|c|c|c|c|c|c|}
\hline \multirow[b]{2}{*}{ Variable studied } & \multicolumn{3}{|c|}{$\begin{array}{l}\text { Men aged } 30 \\
(n=1776) \text { Risk points }\end{array}$} & \multicolumn{3}{|c|}{$\begin{array}{l}\text { Men aged } 35 \\
(n=4332) \text { Risk points }\end{array}$} & \multicolumn{3}{|c|}{$\begin{array}{l}\text { Women aged } 35 \\
(n=1988) \text { Risk points }\end{array}$} & \multicolumn{3}{|c|}{$\begin{array}{l}\text { Women aged } 35 \\
(n=4886) \text { Risk points }\end{array}$} & \multicolumn{4}{|c|}{ Statistical comparison } \\
\hline & 1 & 2 & $3-4$ & 1 & 2 & $3-4$ & 1 & 2 & $3-4$ & 1 & 2 & $3-4$ & $I$ & $I I$ & $I I I$ & $I V$ \\
\hline Use of tobacco & 56.9 & 32.4 & 10.7 & 55.8 & 31.2 & 12.9 & 69.0 & 19.6 & 11.5 & 67.7 & 20.5 & 11.8 & NS & NS & $\star \star \star \star$ & $\star \star \star \star$ \\
\hline Alcohol intake & 63.5 & 25.8 & 10.7 & 64.5 & 23.8 & 11.6 & 94.1 & 5.3 & 0.7 & 93.0 & 6.1 & 0.9 & NS & NS & $\star \star \star$ & $\star \star \star \star$ \\
\hline Dietary intake & 10.5 & 27.9 & 61.6 & 13.6 & 32.8 & 53.6 & 20.3 & 39.4 & 40.3 & 22.2 & 42.1 & 35.7 & $\star \star \star \star$ & $\star \star$ & $\star \star \star \star$ & $\star \star \star \star$ \\
\hline Physical activity & 23.9 & 52.4 & 23.6 & 20.3 & 56.6 & 23.1 & 18.2 & 61.2 & 20.6 & 17.3 & 60.4 & 22.3 & $\star \star$ & NS & $\star \star \star \star$ & $\star \star \star \star$ \\
\hline Psychosocial strain & 91.0 & 7.7 & 1.3 & 90.4 & 7.8 & 1.8 & 88.6 & 9.7 & 1.7 & 88.5 & 9.7 & 1.8 & NS & NS & $\star$ & $\star \star$ \\
\hline Mental stress & 85.2 & 12.0 & 2.8 & 81.0 & 15.4 & 3.6 & 81.3 & 14.8 & 3.8 & 76.3 & 18.1 & 5.5 & $\star \star \star$ & $\star \star \star \star$ & $\star \star$ & $\star \star \star$ \\
\hline
\end{tabular}

${ }^{\star} \mathrm{p}<0.05,{ }^{\star \star} \mathrm{p}<0.01,{ }^{\star \star \star} \mathrm{p}<0.001, \mathrm{NS}=$ no difference of statistical significance.

but there was no difference in tobacco use when moist snuff was included in the analysis. Women aged 35 had a better dietary intake than those aged 30 but experienced more mental stress.

Risk markers

As far as biological risk markers are concerned (table 4), statistically significant differences between 30 year old and 35 year old men were observed for BMI, waist and hip circumferences, WHR, serum cholesterol concentration, and diastolic blood pressure, all these variables being higher in older men. When comparing 30 year old and 35 year old women, statistically significant differences were observed for body height, BMI, waist and hip circumferences, serum cholesterol concentration, and systolic and diastolic blood pressures. All these variables were higher in 35 year old women except for height. Tables 3 and 4 show the pooled results from the first five years.

\section{SEX DIFFERENCES}

Lifestyle factors

Women reported better dietary habits, lower total tobacco use, and lower alcohol consumption than men at both ages (table 3). However, after excluding use of moist snuff from the analysis of tobacco use, more women than men were tobacco users. Men experienced less mental stress and reported less psychosocial strain. More men than women were physically very active (risk point $1, \mathrm{p}<0.001, \chi^{2}$ test) but, on the other hand, more men than women were physically inactive (risk point $3, \mathrm{p}<0.05$ ), statistically significant only for subjects aged 30.

Biological risk markers

As far as the biological risk markers studied are concerned (table 4), significant differences between men and women were observed for all the variables studied $(\mathrm{p}<0.001)$, all being higher in men than in women in both age groups.

COMPARISON BETWEEN THE FIRST AND THE FIFTH YEAR

A comparison between the first and the fifth year was conducted to study potential effects of the intervention programme as a whole. Smoking was less common in 35 year old men as well as in both female age groups examined during the fifth year, and dietary intake was reported to be better in both age and sex groups. Psychosocial strain was reported to be higher in both ages and both sex groups during the fifth year. Mental stress was increased in 35 year old women only. Fewer men and women aged 30 years reported that they were physically inactive ( $<500 \mathrm{kcal} /$ week) during the fifth year.

When comparing biological markers of cardiovascular disease (table 5) during the first and fifth years in 30 year old male participants, one difference of statistical significance was observed, diastolic blood pressure being lower during the fifth year. Among 35 year old men, statistically significant differences were observed for BMI, being higher during the fifth year. In 30 year old women statistically significant differences were observed for serum cholesterol concentration and systolic and diastolic blood pressures, all of them being lower during the fifth year, and in 35 year old women for BMI and WHR, being higher during the fifth year.

COMPARISON DURING A TWO YEAR PERIOD AFTER THE FIRST FIVE YEARS BETWEEN PREVIOUS PARTICIPANTS AND NON-PARTICIPANTS

In 1994 the first people, who had previously been invited at the age of 30, re-appeared when being invited at the age of 35 years. As 30 year

Table 4 Mean values and standard deviations (SD) during the first five years for selected variables included in the health profile

\begin{tabular}{|c|c|c|c|c|c|c|c|c|}
\hline \multirow[b]{3}{*}{ Variable studied } & \multicolumn{4}{|l|}{ Men } & \multicolumn{4}{|c|}{ Women } \\
\hline & \multicolumn{2}{|c|}{ Aged $30(n=1776)$} & \multicolumn{2}{|c|}{ Aged $35(n=4332)$} & \multicolumn{2}{|c|}{ Aged $30(n=1988)$} & \multicolumn{2}{|c|}{ Aged $35(n=4886)$} \\
\hline & Mean & $S D$ & Mean & $S D$ & Mean & $S D$ & Mean & $S D$ \\
\hline Body weight (kg) & 80.3 & 11.5 & 80.8 & 11.4 & 65.1 & 10.9 & 65.6 & 11.0 \\
\hline Body height $(\mathrm{cm})$ & 179.9 & 6.4 & 179.7 & 6.8 & 166.4 & 6.0 & $165.9^{\star}$ & 6.1 \\
\hline $\mathrm{BMI}\left(\mathrm{kg} / \mathrm{m}^{2}\right)$ & 24.8 & 3.2 & $25.0^{\star}$ & 3.1 & 23.5 & 3.6 & $23.8^{\star \star}$ & 3.7 \\
\hline Waist $(\mathrm{cm})$ & 89.0 & 9.0 & $90.1^{\star \star \star}$ & 8.9 & 76.4 & 9.0 & $77.0^{\star}$ & 9.0 \\
\hline Hip $(\mathrm{cm})$ & 101.7 & 6.0 & $102.4^{\star \star \star}$ & 6.0 & 100.0 & 7.6 & $100.9^{\star \star \star}$ & 7.8 \\
\hline WHR $(\mathrm{cm} / \mathrm{cm})$ & 0.87 & 0.06 & $0.88^{\star \star}$ & 0.06 & 0.76 & 0.06 & 0.76 & 0.06 \\
\hline Cholesterol (mmol/1) & 4.97 & 1.04 & $5.29^{\star \star \star}$ & 1.10 & 4.83 & 0.96 & $4.98^{\star \star \star}$ & 0.97 \\
\hline Systolic BP (mm Hg) & 126.4 & 11.9 & 126.4 & 11.9 & 117.7 & 10.8 & $119.3^{\star \star \star \star}$ & 11.6 \\
\hline Diastolic BP (mm Hg) & 78.4 & 9.4 & $80.2^{\star \star \star}$ & 9.2 & 74.9 & 9.2 & $77.0^{\star \star \star}$ & 8.6 \\
\hline
\end{tabular}

${ }^{\star} \mathrm{p}<0.05,{ }^{\star \star} \mathrm{p}<0.01,{ }^{\star \star \star} \mathrm{p}<0.001$, comparison with the younger age group for men and women, respectively. 
Table 5 Mean values and standard deviations (SD) during the first and fifth year for selected variables included in the health profile

\begin{tabular}{|c|c|c|c|c|c|c|c|c|}
\hline \multirow[b]{2}{*}{ Variable studied } & \multicolumn{4}{|l|}{ Men } & \multicolumn{4}{|l|}{ Women } \\
\hline & $\begin{array}{l}\text { Aged } 30 \\
\text { Mean }\end{array}$ & $S D$ & $\begin{array}{l}\text { Aged } 35 \\
\text { Mean }\end{array}$ & $S D$ & $\begin{array}{l}\text { Aged } 30 \\
\text { Mean }\end{array}$ & $S D$ & $\begin{array}{l}\text { Aged } 35 \\
\text { Mean }\end{array}$ & $S D$ \\
\hline First year & $(\mathrm{n}=423)$ & & $(\mathrm{n}=787)$ & & $(n=448)$ & & $(\mathrm{n}=850)$ & \\
\hline $\mathrm{BMI}\left(\mathrm{kg} / \mathrm{m}^{2}\right)$ & 24.7 & 3.0 & 24.8 & 3.0 & 23.3 & 3.5 & 23.5 & 3.8 \\
\hline WHR $(\mathrm{cm} / \mathrm{cm})$ & 0.87 & 0.06 & 0.88 & 0.06 & 0.76 & 0.06 & 0.75 & 0.06 \\
\hline Cholesterol $(\mathrm{mmol} / \mathrm{l})$ & 4.99 & 1.07 & 5.31 & 1.10 & 4.95 & 1.01 & 5.04 & 0.94 \\
\hline Systolic BP (mm Hg) & 127.4 & 12.4 & 126.5 & 11.6 & 118.2 & 11.6 & 120.2 & 11.5 \\
\hline $\begin{array}{l}\text { Diastolic } \mathrm{BP}(\mathrm{mm} \mathrm{Hg}) \\
\text { Fifth year }\end{array}$ & $\begin{array}{l}79.5 \\
(\mathrm{n}=124)\end{array}$ & 9.3 & $\begin{array}{l}79.5 \\
(\mathrm{n}=737)\end{array}$ & 8.9 & $\begin{array}{l}76.2 \\
(n=166)\end{array}$ & 9.4 & $\begin{array}{l}77.0 \\
(\mathrm{n}=852)\end{array}$ & 8.3 \\
\hline $\operatorname{BMI}\left(\mathrm{kg} / \mathrm{m}^{2}\right)$ & 24.8 & 3.0 & $25.2^{\star}$ & 3.1 & 23.5 & 3.8 & $24.1^{\star \star}$ & 3.7 \\
\hline WHR $(\mathrm{cm} / \mathrm{cm})$ & 0.87 & 0.06 & 0.88 & 0.07 & 0.76 & 0.06 & $0.77^{\star \star \star \star}$ & 0.06 \\
\hline Cholesterol $(\mathrm{mmol} / \mathrm{l})$ & 4.89 & 1.10 & 5.24 & 1.08 & $4.70^{\star}$ & 1.07 & 4.98 & 0.95 \\
\hline Systolic BP (mm Hg) & 126.8 & 12.2 & 125.8 & 12.0 & $115.9^{\star}$ & 9.4 & 119.5 & 12.0 \\
\hline Diastolic BP (mm Hg) & $77.2^{\star}$ & 9.5 & 79.9 & 9.72 & $72.3^{\star \star}$ & 8.4 & 76.9 & 9.1 \\
\hline
\end{tabular}

${ }^{\star} \mathrm{p}<0.05,{ }^{\star \star} \mathrm{p}<0.01,{ }^{\star \star \star} \mathrm{p}<0.001$, comparison with corresponding results from the first year.

Table 6 Mean values and standard deviations (SD) in 1994 and 1995 for selected variables included in the health curve in the project "Live for Life" of participants examined twice (in 1989-1990 as well as in 1994-1995) and examined only once (in 1994-1995)

\begin{tabular}{|c|c|c|c|c|c|c|c|c|}
\hline \multirow[b]{3}{*}{ Variable studied } & \multicolumn{4}{|l|}{ Men } & \multicolumn{4}{|l|}{ Women } \\
\hline & \multicolumn{2}{|c|}{$\begin{array}{l}\text { Examined once } \\
(n=506)\end{array}$} & \multicolumn{2}{|c|}{$\begin{array}{l}\text { Examined twice } \\
(n=367)\end{array}$} & \multicolumn{2}{|c|}{$\begin{array}{l}\text { Examined once } \\
(n=593)\end{array}$} & \multicolumn{2}{|c|}{$\begin{array}{l}\text { Examined twice } \\
(n=412)\end{array}$} \\
\hline & Mean & $S D$ & Mean & $S D$ & Mean & $S D$ & Mean & $S D$ \\
\hline $\mathrm{BMI}\left(\mathrm{kg} / \mathrm{m}^{2}\right)$ & 25.9 & 3.4 & 25.6 & 3.3 & 24.5 & 4.0 & 24.5 & 4.0 \\
\hline WHR $(\mathrm{cm} / \mathrm{cm})$ & 0.89 & 0.06 & 0.89 & 0.06 & 0.77 & 0.06 & 0.78 & 0.06 \\
\hline Cholesterol $(\mathrm{mmol} / \mathrm{l})$ & 5.55 & 1.20 & $5.17^{\star \star \star}$ & 0.97 & 5.23 & 1.00 & $5.03^{\star \star}$ & 0.88 \\
\hline Systolic BP (mmHg) & 126.8 & 11.5 & $124.9^{\star}$ & 10.8 & 119.4 & 11.7 & 118.3 & 11.1 \\
\hline Diastolic BP (mmHg) & 80.8 & 8.9 & $79.5^{\star}$ & 8.4 & 77.2 & 9.0 & 76.5 & 8.0 \\
\hline
\end{tabular}

${ }^{\star} \mathrm{p}<0.05,{ }^{\star} \mathrm{p}<0.01$, comparison with corresponding results of those examined only once.

old subjects had not been invited in all communities, a comparison could only be made in 1994 and 1995 between those who had participated at the age of 30 and those who had not. Concerning lifestyle variables, significant differences were observed for smoking in men, and for dietary habits and mental stress in women. Those who had been examined five years before had the best values. As far as biological risk markers are concerned, significant differences were also observed for serum cholesterol concentration both in men and women and for systolic and diastolic blood pressures in men (lower values in those who were examined for the second time). (Table 6).

\section{Discussion}

The Live for Life Programme is based on the premise that lifestyle can have a profound influence on morbidity and mortality and may operate via traditional cardiovascular risk factors. ${ }^{10-23}$ The health profile used in Live for Life is based on assessment of 12 different lifestyle and biological risk factors, which are used both as a definition of risk at baseline and also as an intervention. The use of the health profile may be considered as part of a high risk strategy, but may also be a useful tool for a low risk strategy, especially as the copy is kept by all participants. It is currently believed that such a combined strategy in lifestyle intervention represents an optimal preventive approach. ${ }^{2}$ Evaluating the baseline data collected from this programme is the main purpose of this paper, and may be considered the first step in evaluating the programme as a whole. In this context, it is relevant to consider the issues regarding the study population that was selected, the measurements taken, and generalisability of results.

This intervention was undertaken in 30 year and 35 year olds, based on the idea that prevention of cardiovascular disease should start early in life. This age group has been less intensively studied in epidemiology relative to populations middle aged and upwards. Women are included in this preventive programme for several important reasons. There are important cardiovascular risk factors also for women, even if they have a different risk factor profile than men. ${ }^{10}{ }^{13}{ }^{14}$ Women also have an important role in determining the dietary habits of men and children. Furthermore, although young adult women have low risk of cardiovascular disease, many of the lifestyle factors included in this preventive programme are relevant for cancer and diabetes as well.

The next issue involves measurements that were used to build the individualised health profiles. In this paper, we have distinguished lifestyle factors from biological risk markers for cardiovascular disease. The former include smoking, physical inactivity, diet, alcohol misuse, and psychosocial factors, while the latter include anthropometric data, blood pressure, and serum lipids. Although the prognostic value of both categories of risk factors varies across studies and often by sex, the evidence for their importance was considered strong enough for including them in the health profile of this study. ${ }^{10-23}$ We think that this general distinction is a useful way of evaluating the results, as detrimental changes in lifestyle probably precede changes in biological risk markers. 
Finally, in interpreting the results, it is important to consider issues of representativeness, especially in view of the varying participation rates. The participation rate seemed to fluctuate with the cost of the examination; it was initially free, then with a varying fee. Thus, in agreement with previous studies, ${ }^{32}$ a main reason for decreasing attendance may be a weaker economy and corresponding decreases in resources for primary prevention. As observed in previous studies, ${ }^{25}{ }^{26}$ the attendance rate was higher in women. There is reason to believe that the participants are roughly representative of 30 year and 35 year olds in the communities from which they were sampled. Firstly, there were only few differences in biological risk variables in areas with high and low participation rates. Additionally, when assessing whether communities choosing to include 30 year as well as 35 year olds were representative, it was observed that the biological risk markers of the 35 year olds in participating communities did mainly not differ from those measured in nonparticipating communities.

A preliminary evaluation of the results from the Live for Life programme was made in two ways. The potential effect of the population strategy was studied by comparing the results from the fifth year, when the programme had been working for some years, with those from the first year. The differences in lifestyle factors were mostly in the anticipated direction - that is, improved. The subjects examined during the fifth year reported more psychosocial strain. This was an expected finding and may be explained by societal changes, for instance increased unemployment. The rapid increase in obesity in the western world during the past few decades ${ }^{27}$ was also observed in Skaraborg for men and women aged 35 years, but not for those aged 30.

The effect of the individual based programme was studied by comparing those who had been examined at the age of 30 years with those who had not when examined at the age of 30 years. Again the difference between previous participants and non-participants were moderate but in the hypothesised direction.

In conclusion, the lifestyle related and biological risk levels observed in young adults participating in the Live for Life have enabled us to draw conclusions regarding 30 year and 35 year old men and women in the county as a whole. Some of the results are largely confirmatory of other studies, for example, the observation that biological risk factors increase with age, ${ }^{15}$ 28-30 although comparatively little has been published about changes in lifestyle factors during young adulthood. In this study, most lifestyle factors seemed to worsen between the ages of 30 and 35, with the exception of diet, which improved. As previously reported $^{31} 32$ a "negative" lifestyle was associated with increased WHR and serum cholesterol concentration. This study also confirmed other studies suggesting a better biological risk factor profile in women than in men. ${ }^{10} 1332$ However, it was important to note that sex differences in lifestyle risk factor variables did not unanimously follow this pattern, indicating the potential importance of targeting women as well as men in future lifestyle modification intervention programmes, and starting them early in life. Preliminary results from an evaluation of the population based and the individual based intervention indicated some favourable effects of both, but a more comprehensive evaluation has to be made when conclusions can be drawn from a longer observation period.

Funding: financial support has been given from the County Council of Skaraborg and the Institute of Skaraborg. Conflicts of interest: none.

The authors thank the nurses who carried out the health examinations in a very skilful way.

1 Hälsan i Sverige. Hälsostatistisk årsbok 1991/92 (Health in Sweden. Yearbook of Health Statistics 1991/92). Stockholm: Sweden. Yearbook of Health

2 Stamler J. Lessons from the Helsinki Multifactorial Primary Stamler J. Lessons from the Helsinki Multifactorial Primary
Prevention Trial. Nutr Metab Cardiovasc Dis 1995;5:1-5.

3 Persson L-G, Lindström K, Lingfors H, et al. A study of men aged 33-42 in Habo, Sweden with special reference to cardiovascular risk factors. Design, health profile and characteristics of participants and non-participants. Scand F Soc Med 1994;22:264-72.

4 Mayfield D, Mcleod G, Hall P. The CAGE questionnaire: validation of a new alcoholism screening instrument. $A m \mathcal{F}$ Psychiatry 1974;131:1121-3.

5 Lingfors H, Lindström K, Persson L-G, et al. Evaluation of a pedagogic dietary questionnaire aimed for health surveys. Scand $\mathcal{F}$ Nutr 1994;38:106-11.

6 Saltin B, Grimby G. Physiological analysis of middle-aged and old former athletes. Comparison with still active athletes of the same ages. Circulation 1968;38:1 104-15.

7 Taylor HL, Jacobs Jr DR, Schucker B, et al. A questionnaire Taylor HL, Jacobs Jr DR, Schucker B, et al. A questionnaire
for the assessment of leisure time physical activities. for the assessment of leisu
Chronic Dis 1978;31:741-55.

8 Passmore R, Durnin JVGA. Human energy expenditure. Physiol Rev 1955;35:801-40.

9 Rose GA. The diagnosis of ischaemic heart pain and intermittent claudication in field surveys. Bull World Health Organ 1962;27:645-58.

10 Stokes III J, Kannel WB, Wolf PA, et al. The relative importance of selected risk factors for various manifestations of cardiovascular disease among men and women from 35 to 64 years old: 30 years of follow-up in the Framingham Study. Circulation 1987;suppl V:V65-73

11 Neaton JD, Wentworth D for the Multiple Risk Factor Intervention Trial Research Group. Serum cholesterol, blood pressure, cigarette smoking, and death from coronary heart pressure, cigaret fin sing, and death from coronary heart white men. Arch Intern Med 1992;152:56-64.

12 Doll R, Peto R, Wheatley K, et al. Mortality in relation to smoking: 40 years' observations on male British doctors. smoking: 40 years' observ

13 Bengtsson C. Ischaemic heart disease in women. A study based on a randomised population sample of women and women with myocardial infarction in Göteborg, Sweden. [MD Thesis.] Göteborg: Göteborg University, 1973.

14 Lapidus L, Bengtsson C, Larsson B, et al. Distribution of adipose tissue and risk of cardiovascular disease and death: a 12-year follow-up of participants in the population study of women in Gothenburg, Sweden. BMF 1984;289:125761 .

15 Waaler HT. Height, weight and mortality. The Norwegian experience. Acta Med Scand 1984;suppl 679:1-56.

16 Larsson B, Svärdsudd K, Welin L, et al. Abdominal adipose tissue distribution, obesity, and risk of cardiovascular disease and death: 13 year follow up of participants in the study of men born in 1913. BMF 1984;288:1401-4.

17 Powell KE, Thompson PD, Caspersen CJ, et al. Physical activity and the incidence of coronary heart disease. Annu activity and the incidence of coronar
Rev Public Health 1987;8:253-87.

18 Theorell T. The psycho-social environment, stress, and coronary heart disease. In: Marmot M, Elliott P, eds. Coronary heart disease epidemiology. From aetiology to public health. Oxford: Oxford University Press, 1992:256-73.

19 WHO MONICA Project. Prepared by Tunstall-Pedoe H, Kuulasmaa K, Amouyel P, Arveiler D, Rajakangas A-M, Pajak A. Myocardial infarction and coronary deaths in the World Health Organization MONICA project. Registration procedures, event rates, and case-fatality rates in 38 populations from 21 countries in four continents. Circulation 1994;90:583-612.

20 Johansson I, Hallmans G, Asplund K. Are risk factors for atherosclerosis in an area with high incidence of cardiovas-

21 Breslow L, Enstrom JE. Persistence of health habits and Breslow L, Enstrom JE. Persistence of health habits and
their relationship to mortality. Prev Med 1980;9:469-83.

22 Ornish D, Brown SE, Scherwitz LW, et al. Can lifestyle changes reverse coronary heart disease? The Lifestyle Heart Trial. Lancet 1990;336:129-33. 
23 The Multiple Risk Factor Intervention Trial Research Group. Mortality rates after 10.5 years for participants in the Multiple Risk Factor Intervention Trial. Findings related to a p ori hypotheses of the trial. $7 A M A$ 1990;263:1795-80

24 Christensen B. Characteristics of attenders and non-attender at health examinations for ischaemic heart disease in general practice. Scand F Prim Health Care 1995;13:26-31.

25 Waller D, Agass M, Mant D, et al. Health checks in general practice: another example of inverse care? BMF 1990;300: $1115-18$ 26 Jacobsen BK, Thelle DS. The Tromsø Heart Study: do they differ? Scand $\mathcal{F}$ Soc Med 1988;16:101-4.

27 Prentice AM, Jebb SA. Obesity in Britain: gluttony or sloth? BMF 1995;311:437-9.

28 Mann JI, Lewis B, Shepherd J, et al. Blood lipid concentrations and other cardiovascular risk factors: distribution, tions and other cardiovascular risk factors: distribution,
prevalence, and detection in Britain. BMF 1988;296:1702-6.
29 Huhtasaari F, Asplund K, Wester PO. Cardiovascular risk factors in the Northern Sweden MONICA Study. Acta Med Scand 1988;224:99-108.

30 Walldius $G$, Jungner I. Lämpligt med två gränsvärden vid diagnostik och behandling av högt serumkolesterol (Two limits of serum cholesterol are appropriate in diagnosis and treatment of hypercholesterolaemia). Lakartidningen 1988; 85:3835-9.

31 Persson L-G, Lindström $\mathrm{K}$, Lingfors $\mathrm{H}$, et al. Interrelation between potential risk factors for cardiovascular disease in men aged 33-42 years with special reference to life-style factors. A study from Habo in the County of Skaraborg, Sweden. Eur F Public Health 1994;4:238-44.

32 Persson L-G. Lifestyle oriented prevention programmes within primary health care in Skaraborg, Sweden, with special reference to cardiovascular risk factors. [MD Thesis.] Gothenburg: Göteborg University, 1997. 